Original Article

\title{
Microbiological Quality and Antibiogram Assessment of Bacterial Pathogens Isolated from Raw Salad Vegetable Samples of Kathmandu Valley
}

\author{
${ }^{a}$ Rojan Poudel, ${ }^{a}$ Neha Gautam, ${ }^{a}$ Krishus Nepal, ${ }^{b}$ Binod Lekhak, ${ }^{b}$ Milan Kumar Upreti*

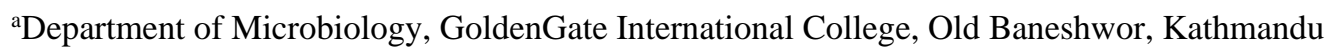 \\ ${ }^{\mathrm{b}}$ Central Department of Microbiology, Tribhuvan University, Kathmandu, Nepal \\ *Corresponding email: milanupreti@gmail.com
}

\begin{abstract}
Most typical salad vegetables include carrots, cabbages, lettuces, bell peppers, cucumber, onions, tomatoes, coriander and radishes. The aim of this research was to study the microbiological quality of salad vegetables and perform antibiotic susceptibility of isolates. In this study, total viable count, total coliform count and yeast, mold count were calculated as $\mathrm{CFU} / \mathrm{ml}$ within sample type and according to various sample sources. Total percentage of isolated bacteria and molds were calculated. Antibiotic sensitivity test of isolated bacteria was carried out by Kirby-Bauer disc diffusion method according to CLSI 2017 guideline. Average microbial count was $\leq 107 \mathrm{CFU} / \mathrm{ml}$ for all sample types. So, it revealed that the vast majority of samples failed to comply with international standards i.e. $\leq 104 \mathrm{CFU} / \mathrm{ml}$. Total 172 isolates from raw salad vegetable Escherichia coli $14(70 \%), \mathrm{K}$. pneumoniae $12(60 \%)$ and $P$. aeruginosa $15(75 \%)$ were found to be predominant. Whereas, Trichoderma spp $4(20 \%)$ were most predominant amongst mold. Highest resistivity was against Amoxicillin/ Clavulanic acid and most sensitivity was against Gentamicin followed by Ciprofloxacin and Chloramphenicol. This study showed that raw salad vegetable samples were heavily contaminated and the antimicrobial resistance pattern shown by the isolates is an indication that adequate measure need be taken to regulate drug use in both humans and animals in order to minimize the risk of increasing antimicrobial resistance.
\end{abstract}

\begin{tabular}{l} 
Article Info \\
\hline Article history: \\
Received date: 30 September 2019 \\
Accepted date: 20 April 2020 \\
\hline \\
Keywords: \\
Salad \\
International Standards \\
Microbiological Quality
\end{tabular}

\section{Introduction}

Vegetables represent a major element of our food sources. Raw vegetables can harbors a pathogenic microorganisms rely on the types of crops, agronomic routine, geographical range of production, and climate condition before harvest, which may get contaminated while growing in farmland or garden or during harvesting, post-harvesting handling, processing and transportation that can highly impact the microbiota pattern (Ahvenainen, 1996; Olaimat \& Holley, 2012). A salad is a term generally related to various food commodities that have a combination of sliced or mince element which may be mainly vegetables or fruits. Most typical salad vegetables include carrots, cabbages, lettuces, bell peppers, cucumber, onions, tomatoes, coriander and radishes (Uwamere et al.,
2013).

In context of Nepal, approximately $75 \%$ of wastewater created inside Kathmandu valley is emptied into waterways without any treatment or with limited treatment, inducing pollution of water reservoirs. Utilization of polluted water reservoirs and untreated sewage or wastewater as a purpose for irrigating vegetables is frequent in the Kathmandu valley (Shrestha et al., 2016). Manure used for improving the growth of crop and salad vegetables contribute a higher number of pathogenic microorganisms those includes; Salmonella spp., Pseudomonas aeruginosa, Escherichia coli, Enterobacter spp., Klebsiella spp., Vibrio spp., Citrobacter spp., Serratia spp., Providencia spp., Yersinia enterocolitica, Aeromonas hydrophila, 
Listeria monocytogenes and Staphylococcus aureus. Accordingly, a greater hazard against public health is posed by the organic fertilizers applied in the farmland (Rahman \& Noor, 2012; Uwamere et al., 2013).

In current years, the significance of prepared salads vegetables as possible carrier of gastrointestinal infection have been come to light by various large outbreaks across international boundaries (Little \& Gillespie, 2008). Furthermore, the existence of antibiotic resistances both in normal flora and pathogenic microorganism in fresh salad vegetables may provide to horizontal spreading of resistances. Capability of transferring elements due to presence of resistance genes can aid the distribution of resistance and the extensive use of antibiotic admits direct selection or co-selection of resistances (De la Cruz \& Davies, 2000; Tenover, 2006). Microorganisms serving as a source for resistance determinants may have high dominance on resistance gene transfer in ordinary habitats, such as human's colon and vegetables surfaces. As a result, the existence of antibiotic-resistant microbes in fresh vegetables that definitely forms further concern for public safety (Aarestrup et al., 2008; Walsh \& Fanning, 2008; Falomir et al., 2010).

\section{Materials and Methods}

Study was conducted from June to December 2018.Simple random sampling was implemented for the collection of sample to study any variances in the contamination level of microbes with respect to the places. A total of 100 raw salad vegetable samples were collected in sterile Ziploc bag from different open market and grocery's shops outlet at Kathmandu, Lalitpur and Bhaktapur districts and transported to laboratory using an ice box and ice packs and processed within 2 hours of collection. In case of delay the samples were stored in the refrigerator. Edible portion of vegetable were included whereas, non-edible part were excluded from the study.

Each samples to be analyzed were sliced/cut into small pieces on a sterile tray using a sterilized knife wearing a pair of latex gloves for every individual sample. $25 \mathrm{~g}$ of each sample was weighed and was mixed in $225 \mathrm{ml}$ of diluent separately to make 10 fold dilution (Ssemanda et al., 2017). One $\mathrm{ml}$ of sample were dispensed into empty sterile petri dishes and sterile molten plate count agar (PCA) and violet red bile agar (VRBA) were poured individually for enumeration of total aerobic count, total coliform count respectively. Then inoculated petri plates were incubated at $37^{\circ} \mathrm{C}$ for $24 \mathrm{~h}$ (Reasoner, 2004; Faourklingbeil et al., 2016) for aerobic and coliform count.

For enumeration of fungi, $0.1 \mathrm{ml}$ of the appropriate dilutions were transferred to the sterile petri dishes and $45^{\circ} \mathrm{C}$ of molten sabourad's dextrose agar (SDA) mixed with $0.1 \%$ chloramphenicol and poured into particular petri plates by spread plate method. Then respective petri dishes were incubated at $25^{\circ} \mathrm{C}$ for 5 days (Mritunjay \& Kumar, 2017). The isolated microorganism were distinguish on the principle of gram staining, simple staining and lacto phenol cotton blue staining (Khanal et al., 2014; collins \& lyne's, 2004).

\subsection{Isolation and Identification of bacterial isolates}

Sample (25 g) was homogenized in $225 \mathrm{ml}$ of sterile peptone water. For Salmonella spp, from homogenized sample $1 \mathrm{ml}$ was suspended in $9 \mathrm{ml}$ Selenite F Broth and incubated for $37^{\circ} \mathrm{C}$ for $24 \mathrm{~h}$. After incubation, enriched culture broths was used to streak on xylose lysine deoxycholate (XLD) plates. Then streaked petri plates were incubated at $37^{\circ} \mathrm{C}$ for $24-48 \mathrm{~h}$. For Pseudomonas aeruginosa, from homogenized sample $1 \mathrm{ml}$ was suspended in $9 \mathrm{ml}$ nutrient broth and incubated at $37^{\circ} \mathrm{C}$ for $24 \mathrm{~h}$. Enriched broth was used to steak on Cetrimide base agar. Then streaked petriplates were incubated at $42^{\circ} \mathrm{C}$ for 24-48h. For Staphylococcus aureus, enriched culture broths was used to streak on MSA plate and incubated at $37^{\circ} \mathrm{C}$ for $24 \mathrm{~h}$. For Coliform, $25 \mathrm{~g}$ sample was homogenized in $225 \mathrm{ml}$ of sterile buffered peptone water and from homogenized sample $1 \mathrm{ml}$ was suspended in $9 \mathrm{ml}$ nutrient broth and incubated at $37^{\circ} \mathrm{C}$ for $24 \mathrm{~h}$. Enriched culture broths was used to streak onto MacConkey agar and incubated at $37^{\circ} \mathrm{C}$ for $24 \mathrm{~h}$. For Vibrio cholerae, $25 \mathrm{~g}$ sample was homogenized in $225 \mathrm{ml}$ of alkaline peptone water and enriched at $37{ }^{\circ} \mathrm{C}$ for $18 \mathrm{~h}$. After enrichment then it was sub-cultured onto TCBS agar and incubated at $37^{\circ} \mathrm{C}$ for 24h. Isolated typical yellow colonies suspected as vibrio cholerae. (Hassan et al., 2011; Allydice-Francis \& Brown, 2012; Jeddi et al., 2014; Abakpa et al., 2015; Rivas et al., 2015; Hounmanou et al., 2016; Castro et al., 2017).

After identification, the antibiotic susceptibility test of the isolates was done by modified Kirby-Baur disk diffusion method as recommended by Clinical Laboratory Standards Institute using Mullen Hilton 
Agar (MHA) (CLSI/NCCLS, 2017). Application of the CLSI guidelines, the susceptibility or resistance of the isolates to individual antimicrobial agents was determined (Shah et al., 2015).

The results of this research were coded and entered in Microsoft office (Excel) version 2013 and move to IBM SPSS Version 22. Statistical analysis was done by mean deviations. P-value $<0.05$ was considered significant.

\section{Results and Discussion}

Sample collected from Bhaktapur showed highest number of contamination across Total viable count (TVC), Total coliform count (TCC) and Yeast mold count (YMC) when compared with other sources. The sample showed statistically non-significant correlation TVC $(\mathrm{P}=0.216)$, TCC $(\mathrm{P}=0.395)$ and $\mathrm{YMC}(\mathrm{P}=0.388)$ within Kathmandu, Lalitpur and Bhaktapur. All vegetable samples were found to be heavily contaminated with microorganism within a range of 3$7.89 \log \mathrm{CFU} / \mathrm{gm}$. Cabbage accounted for higher total viable count whereas coriander i.e. $7.01 \mathrm{log} \mathrm{CFU} / \mathrm{gm}$ and carrot i.e. $6.55 \log \mathrm{CFU} / \mathrm{ml}$ accounted for higher coliform count. Least level of total viable count i.e. $4.98 \log \mathrm{CFU} / \mathrm{ml}$ and coliform count i.e. $4.05 \mathrm{CFU} / \mathrm{ml}$ was observed in Capsicum. Whereas, Cabbage were found to be high in Yeast and mold count and Carrot account for least count i.e. $5.56 \log \mathrm{CFU} / \mathrm{ml}$ and $4.71 \log \mathrm{CFU} / \mathrm{ml}$ respectively. Statistically sample taken for study showed non-significant relation with TVC $(\mathrm{P}=0.281)$, TCC $(\mathrm{P}=0.101)$ and $\mathrm{YMC}(\mathrm{P}=0.236)$.

Among 100 samples analyzed from three different sources, a total of 172 isolates of E. coli was found in higher frequency in all samples, while $K$. oxytoca among the least contaminant i.e. 2 (7\%). Whereas, $V$. cholerae were absence in all sample source. Similarly, of total 41 molds were isolated, Trichoderma spp were most predominant i.e. 4 (20\%) and Penicillium was the least contaminant fungi i.e. 1 (5\%) 1/20. Among them cabbage were found to be most contaminated i.e. While carrots were least contaminated i.e. 5 (12\%).

Among five variety of vegetables selected, cabbage i.e. $46(26 \%)$ were found to be most contaminated while capsicum i.e. $22(12 \%)$ were least contaminated. P.aeruginosa were most predominant i.e. 15 (75\%), followed by Coliform along with, Salmonella spp. and $S$. aureus, which was associated frequently with all types of sample. Whereas there was no evidence for $V$. cholerae within all types of sample.

Table 1: TVC, TCC and Yeast and mold Count in sample sources and sample type

\begin{tabular}{|c|c|c|c|c|c|c|c|}
\hline Sample source & Mean (TVC) & Mean (TCC) & Mean (YMC) & Sample Type & Mean (TVC) & Mean (TCC) & Mean (YMC) \\
\hline Kathmandu & 5.63 & 5.4 & 4.76 & Cabbage & 6.58 & 6.02 & 5.56 \\
\hline Lalitpur & 6.2 & 6.02 & 5.11 & Carrot & 6.23 & 6.55 & 4.71 \\
\hline Bhaktapur & 6.88 & 6.62 & 5.55 & Capsicum & 4.98 & 4.05 & 4.92 \\
\hline- & - & - & - & Coriander & 6.36 & 7.01 & 5.35 \\
\hline- & - & - & - & Lettuce & 6.43 & 5.83 & 4.75 \\
\hline
\end{tabular}

Table 2: Percentage occurrence of bacterial and fungal isolates in samples according to different locations

\begin{tabular}{|c|c|c|c|c|c|c|c|}
\hline Positive isolates & $\begin{array}{l}\text { Kathmandu } \\
(\mathrm{n}=45)\end{array}$ & $\begin{array}{l}\text { Lalitpur } \\
(n=30)\end{array}$ & $\begin{array}{l}\text { Bhaktapur } \\
(n=25)\end{array}$ & Molds & $\begin{array}{l}\text { Kathmandu } \\
(\mathrm{n}=45)\end{array}$ & $\begin{array}{l}\text { Lalitpur } \\
(n=30)\end{array}$ & $\begin{array}{l}\text { Bhaktapur } \\
(n=25)\end{array}$ \\
\hline E.coli & $18(40 \%)$ & $13(43 \%)$ & $20(80 \%)$ & A.niger & $4(9 \%)$ & $3(10 \%)$ & $0(0 \%)$ \\
\hline K.pneumoniae & $17(38 \%)$ & $19(63 \%)$ & $18(72 \%)$ & Trichoderma spp & $2(4 \%)$ & -- & $11(14 \%)$ \\
\hline P.aeruginosa & $13(29 \%)$ & $12(40 \%)$ & $15(60 \%)$ & Cladosoprium spp & $6(13 \%)$ & $1(3 \%)$ & $2(8 \%)$ \\
\hline Citrobacter spp & $9(20 \%)$ & $5(17 \%)$ & $4(16 \%)$ & Mucor spp & $1(2 \%)$ & -- & $2(8 \%)$ \\
\hline K.oxytoca & -- & $2(7 \%)$ & -- & A. fumigatus & -- & $2(7 \%)$ & -- \\
\hline V.cholerae & -- & -- & -- & Geotrichum spp & $1(2 \%)$ & $3(10 \%)$ & $2(8 \%)$ \\
\hline S.aureus & -- & -- & $3(12 \%)$ & Penicillium spp & -- & -- & $1(4 \%)$ \\
\hline Salmonella spp & $3(7 \%)$ & $1(3 \%)$ & $3(12 \%)$ & -- & -- & -- & -- \\
\hline Total : & $0(34 \%)$ & $5230 \%)$ & $65(37 \%)$ & & $14(34 \%)$ & $9(21 \%)$ & $18(43 \%)$ \\
\hline
\end{tabular}


Table 3: Percentage occurrence of bacterial and mold isolates in samples according to vegetables type

\begin{tabular}{|c|c|c|c|c|c|}
\hline Positive isolates & Cabbage $(n=20)$ & Carrot $(n=20)$ & Capsicum (n=20) & Coriander $(n=20)$ & Lettuce $(n=20)$ \\
\hline E.coli & $11(55 \%)$ & $12(60 \%)$ & $6(30 \%)$ & $14(70 \%)$ & $8(40 \%)$ \\
\hline K.pneuтопiae & $12(60 \%)$ & $12(60 \%)$ & $7(35 \%)$ & $10(50 \%)$ & $10(50 \%)$ \\
\hline p.aeruginosa & $15(75 \%)$ & $5(25 \%)$ & $6(30 \%)$ & $9(45 \%)$ & $5(25 \%)$ \\
\hline Citrobacter spp & $5(25 \%)$ & $7(35 \%)$ & $1(5 \%)$ & $3(15 \%)$ & $2(10 \%)$ \\
\hline K.oxytoca & -- & -- & -- & -- & -- \\
\hline V.cholerae & -- & -- & -- & -- & -- \\
\hline S.aureus & $2(10 \%)$ & -- & -- & -- & $1(5 \%)$ \\
\hline Salmonella spp & $1(5 \%)$ & $3(15 \%)$ & $1(5 \%)$ & $2(10 \%)$ & -- \\
\hline Total: & $46(26 \%)$ & $38(22 \%)$ & $22(12 \%)$ & $44(25 \%)$ & $27(15 \%)$ \\
\hline Molds & Cabbage $(n=20)$ & Carrot $(n=20)$ & Capsicum $(n=20)$ & Coriander $(n=20)$ & Lettuce $(n=20)$ \\
\hline A.niger & $3(15 \%)$ & -- & $1(5 \%)$ & $2(10 \%)$ & $1(5 \%)$ \\
\hline Trichoderma spp & $4(20 \%)$ & $2(10 \%)$ & $4(20 \%)$ & $3(15 \%)$ & -- \\
\hline Cladosoprium spp & $3(15 \%)$ & $1(5 \%)$ & -- & $2(10 \%)$ & $3(15 \%)$ \\
\hline Muсor spp & -- & -- & $1(5 \%)$ & -- & $1(5 \%)$ \\
\hline A. fumigatus & -- & -- & -- & $1(5 \%)$ & $1(5 \%)$ \\
\hline Geotrichum spp & -- & $1(5 \%)$ & $1(5 \%)$ & $1(5 \%)$ & $3(15 \%)$ \\
\hline Penicillium spp & -- & $1(5 \%)$ & -- & -- & -- \\
\hline Total & $11(26 \%)$ & $5(12 \%)$ & $7(17 \%)$ & $9(21 \%)$ & $9(21 \%)$ \\
\hline
\end{tabular}

Table 4: Antibiotic susceptibility pattern of E. coli and citrobacter spp

\begin{tabular}{lcccc}
\hline \multirow{2}{*}{ Antibiotics } & \multicolumn{2}{l}{$\boldsymbol{E}$ coli $(\mathbf{n}=\mathbf{5 1})$} & \multicolumn{2}{c}{ Citrobacter spp $(\mathbf{n}=\mathbf{1 8})$} \\
& $(\mathbf{S} \%)$ & $(\mathbf{R} \%)$ & $(\mathbf{S} \%)$ & $(\mathbf{R} \%)$ \\
\hline GEN & $49(96 \%)$ & $2(4 \%)$ & $18(100 \%)$ & -- \\
C & $43(84 \%)$ & $8(16 \%)$ & $16(89 \%)$ & $2(11 \%)$ \\
AMC & $3(6 \%)$ & $48(94 \%)$ & -- & $18(100 \%)$ \\
CTX & $42(82 \%)$ & $9(18 \%)$ & $12(67 \%)$ & $6(33 \%)$ \\
TE & $19(37 \%)$ & $32(63 \%)$ & $18(100 \%)$ & -- \\
COT & $24(47 \%)$ & $27(53 \%)$ & $15(83 \%)$ & $3(17 \%)$ \\
CTR & $49(96 \%)$ & $2(4 \%)$ & $15(83 \%)$ & $3(17 \%)$ \\
CIP & $47(92 \%)$ & $4(8 \%)$ & $18(100 \%)$ & -- \\
\hline
\end{tabular}

*GEN: Gentamycin; C:Chloramphenicol; AMC:

Amoxicillin/ clavulanic acid; CTX: Cefotaxime; TE;

Tetracycline; COT: Cotrimoxazole; CTR: Ceftriaxon; CIP:

Ciprofloxacin; S: Sensitivity and R: Resistance

Escherichia coli 48 (94\%), Klebsiella pneumoniae 50 (98\%), Klebsiella oxytoca 3 (100\%) and citrobacter spp 18 (100\%) were most resistance amoxicillin/ clavulanic acid (AMC). All 40 Pseudomonas aeruginosa isolates were found to be sensitive to Gentamicin (GEN), Ceftazidime (CAZ) and Levofloxacin (LE). Whereas Imipenem (IPM) and Piperacillin/Tazobactam (PIT) were most resistant i.e. $30(75 \%)$ and $16(40 \%)$ respectively. Only total of 3 Staphylococcus aureus isolates were subjected to AST and found to be sensitive to Gentamicin (GEN) and Ciprofloxacin (CIP) i.e. 3 (100\%) respectively. Whereas Ceftazidime (CAZ) and Amikacin (AK) were most resistant i.e. $3(100 \%)$. All total of 6 Salmonella spp isolates were found to be sensitive to Gentamicin
(GEN), Chloramphenicol (C), Ceftriaxone (CTR) and Cefotaxime (CTX) i.e. $6(100 \%)$ respectively. Whereas Amoxicillin/ clavulanic acid (AMC) was most resistant i.e. $2(33 \%)$.

Table 5: Antibiotic susceptibility pattern of $K$. pneumoniae and $K$. oxytoca.

\begin{tabular}{lcccc}
\hline Antibiotics & \multicolumn{2}{l}{$\begin{array}{l}\text { p. pneumoniae } \\
(\boldsymbol{n}=51)\end{array}$} & \multicolumn{3}{l}{ K. oxytoca $(\boldsymbol{n}=3)$} \\
& $(\mathrm{S} \%)$ & $(\mathrm{R} \%)$ & $(\mathrm{S} \%)$ & $(\mathrm{R} \%)$ \\
\hline GEN & $51(100 \%)$ & -- & $3(100 \%)$ & -- \\
C & $51(100 \%)$ & -- & $3(100 \%)$ & -- \\
AMC & $1(2 \%)$ & $50(98 \%)$ & -- & $3(100 \%)$ \\
CTX & $33(65 \%)$ & $18(35 \%)$ & $3(100 \%)$ & -- \\
TE & $39(76 \%)$ & $12(24 \%)$ & $3(100 \%)$ & -- \\
COT & $47(92 \%)$ & $4(8 \%)$ & $2(67 \%)$ & $1(33 \%)$ \\
CTR & $44(86 \%)$ & $7(14 \%)$ & $3(100 \%)$ & -- \\
CIP & $51(100 \%)$ & -- & $3(100 \%)$ & -- \\
\hline
\end{tabular}

*GEN: Gentamycin; C:Chloramphenicol; AMC: Amoxicillin/ clavulanic acid; CTX: Cefotaxime; TE; Tetracycline; COT: Cotrimoxazole; CTR: Ceftriaxon; CIP: Ciprofloxacin; S: Sensitivity and $R:$ Resistance

Table 6: Antibiotic susceptibility pattern of $P$. aeruginosa $(\mathrm{n}=40)$

\begin{tabular}{lcc}
\hline Antibiotic & Sensitive (S \%) & Resistant (R \%) \\
\hline GEN & $40(100 \%)$ & -- \\
PIT & $24(60 \%)$ & $16(40 \%)$ \\
CAZ & $40(100 \%)$ & -- \\
IPM & $10(25 \%)$ & $30(75 \%)$ \\
LE & $40(100 \%)$ & -- \\
\hline
\end{tabular}

*GEN: Gentamycin; C:Chloramphenicol; AMC:

Amoxicillin/ clavulanic acid; CTX: Cefotaxime; TE;

Tetracycline; COT: Cotrimoxazole; CTR: Ceftriaxon; CIP:

Ciprofloxacin 
Table 7: Antibiotic susceptibility pattern of $S$. aureus $(\mathrm{n}=3)$

\begin{tabular}{lll}
\hline Antibiotics & S \% & R \% \\
\hline GEN & $3(100 \%)$ & -- \\
CIP & $3(100 \%)$ & -- \\
CAZ & -- & $3(100 \%)$ \\
AK & -- & $3(100 \%)$ \\
TE & $2(67 \%)$ & $1(33 \%)$ \\
E & $2(67 \%)$ & $1(33 \%)$ \\
P & $1(33 \%)$ & $2(67 \%)$ \\
\hline
\end{tabular}

*GEN: Gentamycin; C:Chloramphenicol; AMC:

Amoxicillin/ clavulanic acid; CTX: Cefotaxime; TE;

Tetracycline; COT: Cotrimoxazole; CTR: Ceftriaxon; CIP: Ciprofloxacin

Table 8: Antibiotic susceptibility pattern of Salmonella spp. $(\mathrm{n}=6)$

\begin{tabular}{lcc}
\hline Antibiotics & Sensitive (S \%) & Resistant (R \%) \\
\hline GEN & $6(100 \%)$ & -- \\
C & $6(100 \%)$ & -- \\
AMC & $4(67 \%)$ & $2(33 \%)$ \\
CTX & $6(100 \%)$ & -- \\
TE & $5(83 \%)$ & $1(17 \%)$ \\
COT & $5(83 \%)$ & $1(17 \%)$ \\
CTR & $6(100 \%)$ & -- \\
CIP & $5(83 \%)$ & $1(17 \%)$ \\
NA & $5(83 \%)$ & $1(17 \%)$ \\
\hline
\end{tabular}

*GEN: Gentamycin; C:Chloramphenicol; AMC:

Amoxicillin/ clavulanic acid; CTX: Cefotaxime; TE;

Tetracycline; COT: Cotrimoxazole; CTR: Ceftriaxon; CIP: Ciprofloxacin

In this study, it was found that the average total viable count, total coliform count and yeast mold count were higher in Bhaktapur followed by Lalitpur and Kathmandu and the salad vegetable sample showed statistically non-significant correlation $(p<0.05)$ between these three sample sources i.e. TVC $(\mathrm{P}=0.216)$, TCC $(\mathrm{P}=0.395)$ and $\mathrm{YMC}(\mathrm{P}=0.388)$. The salad vegetables that were examined in this showed non-significant relation $(\mathrm{P}<0.05)$ with total viable count, total coliform count and yeast mold count i.e. TVC $(\mathrm{P}=0.281)$, TCC $(\mathrm{P}=0.101)$ and YMC $(\mathrm{P}=0.236)$. Similar conclusion was reported by Wagle (2015). Comparatively, lower microbial load was observed in capsicum amongst all other salad vegetable sample i.e. $\leq 10^{4} \mathrm{CFU} / \mathrm{ml}$ as similar to study conducted in the US by Tournas, 2005. It could be because of the fact that capsicum or green peppers had lesser count as they have smooth, waxy and hard skin which does not allows microbes to reach inside and proliferate (Tournas, 2005). In this study, overall Cabbage and lettuce were found to be higher in total viable count i.e. $\leq 10^{6} \mathrm{CFU} / \mathrm{ml}$ which, may be due to the fact that leafy vegetable like these have high folds and the higher surface area which make more susceptible to trapping dirt, irrigation water or soil in the folds (Aycicek et al., 2006). Also, in this study Coriander and Carrot show considerably high coliform counts i.e. $\leq 10^{7} \mathrm{CFU} / \mathrm{ml}$. Similar, conclusion was reported by Mritunjay et al. (2017) and Ahmed et al. (2019), where total coliform range from 3.0 to $7.8 \mathrm{log}$ CFU/g and 4.60 to $7.40 \mathrm{log}$ $\mathrm{CFU} / \mathrm{g}$ respectively. In this study, Cabbage were found to be high in Yeast and mold count. Whereas Carrot account for least Yeast and mold count i.e. $5.56 \mathrm{log}$ $\mathrm{CFU} / \mathrm{ml}$ and $4.71 \mathrm{CFU} / \mathrm{ml}$ respectively. The average range for Yeast and mold count were 3.02-6.99 $\mathrm{CFU} / \mathrm{ml}$. Similar, finding were observed in a study by Jeddi et al. (2014).

Among 100 samples examined, Escherichia coli, $K$. pneumoniae and $P$. aeruginosa were the common pathogens found to be predominant within samples typesi.e. Coriander 14(70\%) 14/20, Cabbage and carrot 12(60\%) 12/20, Cabbage 15(75\%) 15/20 respectively. Similar result were observed in other study (Tambekar et al., 2006) ,where E.coli was predominant (38.3\%) followed by Pseudomonas spp. (16.2\%), S. aureus $(15.1 \%)$ and Salmonella spp (5.8\%). However, in this study conclusion regarding $S$. aureus were higher than those reported in a study from UK (2.7\%), Meldrum et al., 2009. The presence of $S$. aureus in salad vegetables from different sources found in this study is an indication of poor hygienic practices (Scharff, 2012). Similarly, in this study Salmonella spp contamination were higher as compare to a study in Spain (Abadias et al., 2008). Salmonella spp could arise from washing vegetables with contaminated water or handling of vegetables by infected workers (Tambekar et al., 2006).

Out of 100 sample, total of 41 mold were isolated from the sample collected for this study. Among them Trichoderma spp were most predominant and Penicillium spp were among the least contaminant fungi i.e. Carrot 1 (5\%) 1/20. Other study (Jeddi et al., 2014) showed molds like Penicillium (15.6\%) and Cladosporium (35\%) as a major contaminants. Similarly, finding by other study (Uzeh et al., 2009) reported Mucor spp, Aspergillus fumigatus, Trichoderma and Aspergillus Niger were predominant in salad sample.

Total of 172 isolates were subjected to antibiotic susceptibility test where all coliform isolates were most resistance to amoxicillin/ clavulanic acid (AMC). Only total of 3 Staphylococcus aureus isolates were 
subjected to AST and found to be sensitive to Gentamicin (GEN) and Ciprofloxacin (CIP) i.e. $3(100 \%)$ respectively and resistant to Ceftazidime (CAZ) and Amikacin (AK) (100\%). All total of 6 Salmonella spp isolates were found to be sensitive to Gentamicin (GEN), Chloramphenicol (C), Ceftriaxone (CTR) and Cefotaxime (CTX) i.e. 6 (100\%) respectively. Whereas Amoxicillin/ clavulanic acid (AMC) was most resistant i.e. 2 (33\%). Similar finding were reported by Falomir et al., 2010 where, out of 106 isolates, 86 isolates were resistant to amoxicillin/clavulanic acid (81\%), 2 resistant isolates in co-trimoxazole (2\%), 3 resistant isolates streptomycin (3\%), 3 resistant isolates in cefotaxime (3\%), 2 resistant isolates in chloramphenicol (2\%) and 1 resistant isolate in ceftazidime (1\%). All total of 40 Pseudomonas aeruginosa isolates were found to be sensitive to Gentamicin (GEN), Ceftazidime (CAZ) and Levofloxacin (LE) i.e. 40 (100\%).whereas Imipenem (IPM) and Piperacillin/Tazobactam (PIT) were most resistant i.e. $30(75 \%)$ and $16(40 \%)$ respectively. Similar conclusion were found by Allydice-Francis and Brown (2012). However, it was antagonistic to this study where Imipenem were most resistant as compare to the result of Imipenem which were most sensitive. This may be due to the fact that Fresh raw vegetables may provide to this anomaly, as epiphytic bacteria may develop antibiotic resistances as a consequence of the large amount of antibiotics used in agriculture, and also treating soil with organic fertilizers, such as sewage sludge and manure, and contaminated irrigation water, may lead to vegetable contaminations with resistant bacteria from animal origin and/or human sources (De la Cruz \& Davies, 2000; Boehme et al., 2004).

\section{Conclusions}

This research work result determine that all of the 5 types of vegetable collected from different parts of Kathmandu valley failed to comply with international standards which is $\leq 10^{4} \mathrm{CFU} / \mathrm{ml}$. Despite the high microbial counts obtained for some of the samples in this study, it is important to note that these samples did not show any visible signs of spoilage. Thus outward appearance may not be a standard parameters for judging the microbial quality of vegetables salad. Presence of coliform bacteria showed as indicators of fecal contamination by human, animal or irrigation water and organic fertilizers. Potential pathogenic bacteria isolated were, Pseudomonas spp,
Staphylococcus spp., and Salmonella spp. These bacteria possess a health risk to consumers.

From the study it was also found that vegetables were also contaminated with mold. Moreover, most of the bacterial isolates showed multi-drug resistance to more than 3 antimicrobial agents. Where Amoxicillin/ clavulanic acid (AMC) was most resistant. So, this study confirms the presence of potential pathogenic microorganism in salad vegetable samples.

\section{Acknowledgments}

The authors are thankful to the faculties, staffs of laboratory at Goldengate International College for their constant guidance, kind encouragement and supervision.

\section{Conflicts of Interest}

The authors declare no conflicts of interest.

\section{Funding}

This research received no external funding

\section{References}

Ahvenainen, R. (1996). New approaches in improving the shelf life of minimally processed fruit and vegetables. Trends in Food Science \& Technology, 7(6), 179-187.

Allydice-Francis, K., \& Brown, P. D. (2012). Diversity of antimicrobial resistance and virulence determinants in pseudomonas aeruginosa associated with fresh vegetables', International Journal of Microbiology, 1-7. doi: $10.1155 / 2012 / 426241$.

Aycicek, H., Oguz, U., \& Karci, K. (2006). Determination of total aerobic and indicator bacteria on some raw eaten vegetables from wholesalers in Ankara, Turkey. International Journal of Hygiene and Environmental Health, 209(2), 197-201.

Boehme, S., Werner, G., Klare, I., Reissbrodt, R., \& Witte, W. (2004). Occurrence of antibiotic-resistant enterobacteria in agricultural foodstuffs. Molecular nutrition \& food research, 48(7), 522-531.

Castro, A., Palhau, C., Cunha, S., Camarinha, S., Silva, J., \& Teixeira, P. (2017). Virulence and resistance profile of Staphylococcus aureus isolated from food. Acta Alimentaria, 46(2), 231-237. 
De la Cruz, F., \& Davies, J. (2000). Horizontal gene transfer and the origin of species: lessons from bacteria. Trends in microbiology, 8(3), 128-133.

Falomir, M. P., Gozalbo, D., \& Rico, H. (2010). Coliform bacteria in fresh vegetables: from cultivated lands to consumers. Current research, technology and education topics in applied microbiology and microbial biotechnology, 2, 1175-1181.

Faour-Klingbeil, D., Todd, E. C., \& Kuri, V. (2016). Microbiological quality of ready-to-eat fresh vegetables and their link to food safety environment and handling practices in restaurants. LWT - Food Science and Technology, 74, 224-233.

Hassan, S. A., Altalhi, A. D., Gherbawy, Y. A., \& ElDeeb, B. A. (2011). Bacterial load of fresh vegetables and their resistance to the currently used antibiotics in Saudi Arabia. Foodborne pathogens and disease, 8(9), 1011-1018.

Hounmanou, Y. M., Mdegela, R. H., Dougnon, T. V., Mhongole, O. J., Mayila, E. S., Malakalinga, J., ... \& Dalsgaard, A. (2016). Toxigenic Vibrio cholerae $\mathrm{O} 1$ in vegetables and fish raised in wastewater irrigated fields and stabilization ponds during a noncholera outbreak period in Morogoro, Tanzania: an environmental health study. BMC research notes, 9(1), 466.

Jeddi, M. Z., Yunesian, M., Gorji, M. E. H., Noori, N., Pourmand, M. R., \& Khaniki, G. R. J. (2014). Microbial evaluation of fresh, minimally-processed vegetables and bagged sprouts from chain supermarkets. Journal of health, population, and nutrition, 32(3), 391-399.

Khanal $\mathrm{P}$ et al. Biotechnological production of inducible defense-related proteins in edible radish (Raphanus Sativus) found in Nepal. Journal of Clinical and Diagnostic Research, 2014, 8(1), 112115.

Little, C. L., \& Gillespie, I. A. (2008). Prepared salads and public health. Journal of Applied Microbiology, 105(6), 1729-1743.

Meldrum, R. J., Little, C. L., Sagoo, S., Mithani, V., McLauchlin, J., \& De Pinna, E. (2009). Assessment of the microbiological safety of salad vegetables and sauces from kebab take-away restaurants in the United Kingdom. Food Microbiology, 26(6), 573577.
Mritunjay, S. K., \& Kumar, V. (2017). A study on prevalence of microbial contamination on the surface of raw salad vegetables. 3 Biotech, 7(1), 13.

Olaimat, A. N., \& Holley, R. A. (2012). Factors influencing the microbial safety of fresh produce: a review. Food Microbiology, 32(1), 1-19.

Rahman, F., \& Noor, R. (2012). Prevalence of pathogenic bacteria in common salad vegetables of Dhaka Metropolis. Bangladesh Journal of Botany, 41(2), 159-162.

Reasoner, D. J. (2004). Heterotrophic plate count methodology in the United States. International journal of food microbiology, 92(3), 307-315.

Rivas, L., Mellor, G. E., Gobius, K., \& Fegan, N. (2015). Detection and typing strategies for pathogenic Escherichia coli. New York, NY : Springer New York.

Sabbithi, A., Naveen Kumar, R., Kashinath, L., Bhaskar, V., \& Sudershan Rao, V. (2014). Microbiological quality of salads served along with street foods of Hyderabad, India. International Journal of Microbiology, 2014. https://doi.org/10.1155/2014/932191

Scharff, R. L. (2012). Economic burden from health losses due to foodborne illness in the United States. Journal of food protection, 75(1), 123-131.

Shah, M. S., Eppinger, M., Ahmed, S., Shah, A. A., Hameed, A., \& Hasan, F. (2015). Multidrugresistant diarrheagenic E. coli pathotypes are associated with ready-to-eat salad and vegetables in Pakistan. Journal of the Korean Society for Applied Biological Chemistry, 58(2), 267-273.

Shrestha, S., Haramoto, E., Sherchand, J. B., \& Junko, S. (2016). Detection of coliform bacteria in irrigation water and on vegetable surfaces in the Kathmandu Valley of Nepal. Journal of Institute of Medicine, 38(1), 43-47.

Ssemanda, J. N., Reij, M., Bagabe, M. C., Muvunyi, C. M., Joosten, H., \& Zwietering, M. H. (2017). Indicator microorganisms in fresh vegetables from "farm to fork" in Rwanda. Food Control, 75, 126133.

Tambekar, D. H., \& Mundhada, R. H. (2006). Bacteriological quality of salad vegetables sold in Amravati City (India). Journal of biological Sciences, 6(1), 28-30. 
Tenover, F. C. (2006). Mechanisms of antimicrobial resistance in bacteria. The American journal of medicine, 119(6), S3-S10.

Tournas, V. H. (2005). Moulds and yeasts in fresh and minimally processed vegetables, and sprouts. International Journal of Food Microbiology, 99(1), 71-77.

Uwamere, O. O., Nosa, O. O., Wakil, A. T., Frances, O. N., Eseosa, U., \& Ozede, I. (2013).
Bacteriological quality of vegetable salads sold at restaurants within Okada Town, Edo State, Nigeria. IOSR Journal of Pharmacy and Biological Sciences (IOSR-JPBS), 5(2), 87-90.

Uzeh, R. E., Alade, F. A., \& Bankole, M. (2009). The microbial quality of pre-packed mixed vegetable salad in some retail outlets in Lagos, Nigeria. African Journal of Food Science, 3(9), 270-272.

(C) 2020 by the authors. Submitted for possible open access publication under the terms and conditions of the Creative Commons Attribution (CC BY) license (http://creativecommons.org/licenses/by/4.0/).

How to cite: Poudel, R., Gautam, N., Nepal, K., Lekhak, B., \& Upreti, M. K. (2020). Microbiological Quality and Antibiogram Assessment of Bacterial Pathogens Isolated from Raw Salad Vegetable Samples of Kathmandu Valley. Himalayan Journal of Science and Technology, 3-4, 88-95. 